\title{
Effect of Transcutaneous Electrical Nerve Stimulation and Faradic Current Stimulation on the Recovery of Bell's Palsy
}

\author{
Emad Eldin Mohamed Abdelatief \\ Department of Basic Science, Faculty of Physical Therapy, October 6 University, Egypt
}

Received September 19, 2020; Revised November 16, 2020; Accepted November 29, 2020

\section{Cite This Paper in the following Citation Styles}

(a): [1] Emad Eldin Mohamed Abdelatief, "Effect of Transcutaneous Electrical Nerve Stimulation and Faradic Current Stimulation on the Recovery of Bell's Palsy," International Journal of Human Movement and Sports Sciences, Vol. 8, No. 6, pp. 369 - 380, 2020. DOI: 10.13189/saj.2020.080608.

(b): Emad Eldin Mohamed Abdelatief (2020). Effect of Transcutaneous Electrical Nerve Stimulation and Faradic Current Stimulation on the Recovery of Bell's Palsy. International Journal of Human Movement and Sports Sciences, 8(6), 369 - 380. DOI: 10.13189/saj.2020.080608.

Copyright $@ 2020$ by authors, all rights reserved. Authors agree that this article remains permanently open access under the terms of the Creative Commons Attribution License 4.0 International License

\begin{abstract}
Background: Bell's palsy is one of the most common problems that affect motor neurons of facial muscles either unilateral or bilateral. It affects the function and quality of life frequently. Therefore, physiotherapists focus on restoring the facial function with different modalities. Electrical stimulation is one of these modalities included in the physiotherapy program to enhance recovery of Bell's palsy. Purpose: The aim of this study was to examine the effect of transcutaneous electrical nerve stimulation and faradic current stimulation on the recovery of Bell's palsy. Methods: One hundred and ninety-six patients from both genders with unilateral Bell's palsy; their ages ranged from 15 to 60 years. They were divided randomly into four groups with forty-nine patients in each group. Group A received conventional therapy, group B received transcutaneous electrical nerve stimulation (TENS), group C received faradic current stimulation, and group D received TENS + faradic current. All patients were assessed at the initial treatment (after 2 weeks of onset), after one month, and at the end of the study by using the House Brackmann Scale (HBS) for the severity of symptoms and facial symmetry which consist of six grades from normal to total paralysis. Results: In group B, there was a statistically significant improvement in grade IV, V, and VI compared to groups A, C, and D while there was no statistically significant difference among the four groups on grade II and III. Conclusion: TENS is more effective in treating moderately severe dysfunctions as well as total
\end{abstract}

paralysis than convention therapy, faradic current and TENS plus faradic current in patients with acute Bell's palsy.

Keywords Bell's Palsy, Transcutaneous Electrical Nerve Stimulation, Faradic Current Stimulation, House Brackmann Scale

\section{Introduction}

Bell's palsy is an idiopathic paralysis that affects more than half of the lower facial muscles as a result of injury to the seventh cranial nerve, and its symptoms are either weakness in the facial muscles or complete paralysis [1]. It affects all age groups, including children, youth, adult, and older people, and its rate between men and women is equal, but it increases in the last stages of pregnancy, and its incidence worsens with diabetes patients [2,3]. About $70 \%$ of cases of Bell's palsy appear on one side of the face and it can also affect both sides of the face at the same time. The incidence of Bell's palsy increases in winter, and this may be due to exposure of the face and neck area to cold air, which leads to nerve inflammation [4].

Although the leading cause of the palsy is not yet clear, it is associated with exposure to a viral infection, air draft, 
inflammation of the nerve which in turn blocks transmission of impulses along the nerve, diabetes, and infection of the upper respiratory tract [5].

Symptoms start quickly and lightly until it reaches total paralysis on one side of the face, and this occurs within hours to days, as the symptoms vary in severity from one person to another, and it is an accumulation of food in one side, difficulty with drinking, inability to raise an eyebrow, headache, high sensitivity to surrounding sounds loss of nasolabial groove and in some cases, loss of taste sensation [6]. The global incidence rate of paralysis is approximately 11 to 40 cases per 100,000 people [7], with its incidence peaking usually between the ages of 15 and 60 years [8].

Approximately $85 \%$ of the patients with Bell's palsy get complete recovery within about three weeks after the onset without any medical intervention or/and physiotherapy treatment, while $15 \%$ of these cases recover after 3 to 6 months of the onset. However, a few cases may have permanent muscle weakness or other problems on the affected side of the face [9].

Treatment of Bell's palsy has a wide range of intervention including corticosteroids to control inflammation and decrease pain resulting from compression on the nerve, in addition to physiotherapy modalities as electrotherapy, massage, heating, ultrasound, laser, exercises and acupuncture to hasten the recovery as well as surgical management to improve outcomes for the cases that are not recovered. The selection between these interventions depends on the severity of symptoms which may be mild, moderate or severe, and the type of injury which may be neuropraxia, axonotmesis, or neurotmesis [11].

Physiotherapy is one of the methods used immediately after the onset of bell's palsy to enhance recovery and improve the psychological status of patients as Bell's palsy rapidly affects the quality of life [12]. Although there is a lack of evidence of the use of the electrical stimulation (ES) either TENS or faradic current, some studies suggest the use of electrical stimulation that may restore function and increase the speed of recovery by maintaining the tone of the facial muscles of the affected side $[12,14]$.

Measuring the extent of improvement in Bell's palsy is an important stage in treatment, so the choice between diagnostic methods must be accurate and based on reliability and validity to document the changes in outcomes before and after the treatment of Bell's Palsy is over. Although there are several scales and questionnaires are used for assessment of facial function, such as the House Brackmann scale [15,16], the Facial Disability Index, the Facial Nerve Paralysis Questionnaire, the Facial Clinimetric Evaluation (FaCE) scale and Synkinesis Assessment Questionnaire (SAQ), the House Brackmann Scale is one of the most used scales to assess facial function as it consists of 6 grades: grade I represents normal, grade II mild, grade III moderate, grade IV moderate to severe, grade V severe, and grade VI total paralysis. It is used to document the outcomes of using electrical stimulation in treating the Bell's palsy [17].

\section{Methodology}

\section{Subjects}

One hundred and ninety-six patients from both genders (94 males and 102 females) with unilateral Bell's palsy (100 right sides and 96 left sides) referred to physiotherapists by neurologists. They were collected from Toukh General Hospital with ages ranged from 15 to 60 years. They involved in the study from December 2018 to May 2020 and were divided randomly into 4 groups with 49 patients in each group. Group A received conventional therapy, group B received TENS in addition to conventional therapy, group $\mathrm{C}$ received faradic current stimulation plus conventional therapy, and group D received TENS and faradic electrical current with conventional therapy. The study was approved by the ethical committee of Toukh General Hospital. A written consent form for participation and publication of the results has been signed by each patient before the treatment with concealing their identity and photographic material confidential. Inclusive criteria for this study include patients with less than 30 days post-onset of Bell's palsy lower motor neuron lesion while Exclusive criteria include patients with bilateral affection of Bell's palsy or any sensory impairment in the area of electrode placement, pregnant women, upper motor neuron lesion and diabetic patients.

\section{Randomization Method}

All participants were divided randomly in each group by using random assignment software (one of the items of the best Randoms Tool). It is a simple online software where participants' data, either names or numbers, were entered and quantifies the quantity in each group were also entered, then the software generated numbers or names of participants in separate 4 groups without duplication [18].

\section{Assessment Tool}

\section{House Brackmann (HB) Scale}

The House Brackmann scale is a grading scale used to assess the functional recovery of facial muscles by detecting symmetry at rest and measuring movements of the eyebrow (upwards or superior movements) and movement of mouth (outwards or lateral movements). The face is divided by two lines: a vertical line that represents a movement of the mouth and a horizontal line that 
represents a movement of the eyebrow. Each line contains four points with $0.25 \mathrm{~cm}$ of movement in each point to complete $1 \mathrm{~cm}$. If the movement of eyebrow and mouth completes $1 \mathrm{~cm}$, this indicates that the functional movement of the face is normal with a total score of 8 while below this score (8/8) the dysfunction of facial muscles is graded from mild dysfunction to total paralysis $[19,20,21]$. All patients were assessed at initial treatment (after 2 weeks of onset), after one month of treatment, and at the end of the study (after 2 months).

\section{Grade I - Normal}

Normal eyebrow and mouth movement with symmetry at rest and at the movement

\section{Grade II - Mild Dysfunction}

Total description: Very slight weakness on the affected side with or without synkinesis

At rest: Normal tonal symmetry

During the movement: Forehead - moderate to good movement; eye - close completely with minimum effort; mouth - mild asymmetry.

\section{Grade III - Moderate Dysfunction}

Total description: Clear difference but not distorted between two sides; noticeable but not severe synkinesis, contracture, and/or hemifacial spasm.

At rest: Normal tonal symmetry

During the movement: Forehead - slight to moderate movement; eye - close completely with effort; mouth slightly weak with maximum effort.

\section{Grade IV - Moderately Severe Dysfunction}

Total description: Visible weakness and/or distorted asymmetry

At rest: Normal tonal symmetry

During the movement: Forehead - none; eye - closes incompletely; mouth - asymmetric with maximum effort.

\section{Grade V - Severe Dysfunction}

Total description: Only hardly perceptible motion

At rest: Tonal asymmetry

During the movement: Forehead - none; eye incomplete closure; mouth - slight movement

\section{Grade VI - Total Paralysis}

No eyebrow or mouth movement

\section{Treatment Procedure}

After the assessment of each patient by the HB scale. The following procedures were applied according to the program of each group: the session started by electrical stimulation followed by exercises and finished by infrared, massage and vibration to reduce lactic acid accumulation. All patients involved in this study were recommended to continue taking medications under the supervision of a neurologist.

\section{Electrical Stimulation}

Medserve.Ltd, Prostim / ET3000, S/N:0314, made in England, was used to deliver both TENS and faradic current stimulation to facial muscles.

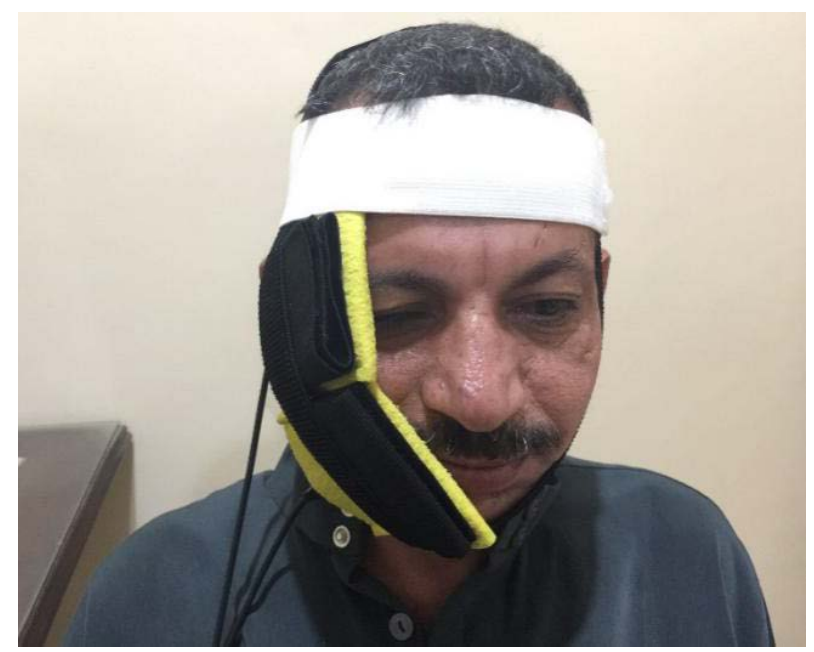

Figure 1. TENS application

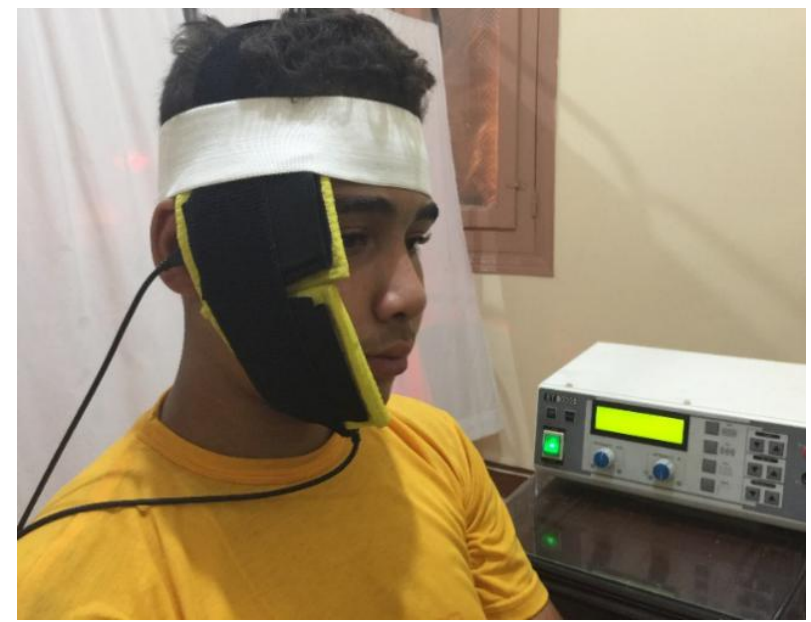

Figure 2. Faradic current application

Transcutaneous electrical nerve stimulation was applied under these parameters: Pulse rate: $100 \mathrm{~Hz}$, stimulate time: 30 seconds, polarity: +, sweep:1Hz, sweep time: 1second, ramp up: off, ramp down: off and time rest: off. The patient was seated on a back supported chair with the head in a neutral position. Two electrodes were used in stimulation (6x8 cm diameter), each electrode covered with wet sponge to allow good electrical transmission. An electrode was placed on the area between the upper part of the zygomatic bone and lateral aspect of the eyebrow while the other electrode was placed on the area between the lower part of the zygomatic bone and mentalis muscle, the two electrodes were fixed by two straps, one around 
head horizontally and the other around mandible and the head vertically Fig. (1). The intensity was increased gradually to produce a minimally visible contraction of the muscles of the affected side (visible muscle twitching). Faradic current stimulation was applied under these parameters: Pulse rate: $100 \mathrm{~Hz}$, stimulate time: $10 \mathrm{sec}$, polarity: +, ramp up: 3 seconds, ramp down: 3 seconds, pulse time: $100 \mu$ s, pause time: $1 \mathrm{~ms}$. The patient position was the same as in TENS. The intensity was increased gradually until the tetanic contraction was visible. The electrodes were placed in the outer socket of the spongy to reduce chemical reaction on the skin. Fig. (2).

\section{Exercises}

After electrical stimulation, the patients were asked to stay in the same position (sitting) in front of a mirror to practice exercises on both sides to maintain symmetry and feedback. The exercises were repeated for ten times to avoid fatigue as the following:

- $\quad$ Raise your eyebrows together for five seconds then relax.

- Raise your eyebrows in a repetitive 5 cycles each cycle for 1 second.

- Raise your eyebrows while resistance has been applied to the sound eyebrow.

- $\quad$ Close your eyes together for five seconds then relax.

- Close your eyes together then tightly flare nostrils by blowing your nose out.

- $\quad$ Squeeze both nostrils as if you were trying to sniff

- Try to smile and open the mouth of the affected side.

- Compress your cheek and puckering your lips.

- Tighten your chin and neck to eventually pull your lower lip down to expose your lower teeth.

- Try to keep your involved eye open while a piece of cotton has been moved on eyelid up and down.

\section{Infrared}

Infrared radiation (Incandescent Heat Lamp R40 Flood Light Bulb: 250 Watts, 120 volts, manufactured by Philips) was applied to the affected side with the patient in the same position (sitting) and the lamp of infrared at $50 \mathrm{~cm}$ from the side of the face for fifteen minutes.

\section{Massage}

After the application of infrared, the patient was asked to lie in a supine position with the head rested on a small pillow to apply face massage. The massage was applied for 20 minutes; 5 minutes general massage and 15 minutes over the forehead area, cheek area, and lower facial area.

As for the general massage, it included a circular massage from the sound side toward the affected side by using the last three fingers of both hands, effleurage massage including picking up, kneading, and wringing to mobilize the muscles and improve circulation and tapping on both sides from the chin to the forehead area.

As for the massage of the other three areas, it was as follows:

\section{Massage of the forehead}

- Circular movement from the lateral border of the eyebrow of the affected side to the lateral border of the eyebrow of the sound side. This movement was applied in three transverse lines over the eyebrow until it reached the hairline.

- Crisscross movement by middle and ring fingers of both hands where the forehead area was moved down and up in an oblique manner.

- $\quad$ Stroking movement: the middle and ring fingers of both hands were sliding to the center of the forehead; then the fingers were drawn down toward the temples with a rotary movement.

- $\quad$ Sliding movement of the brow and the eye was applied by the middle and ring fingers from the inner corner of the affected eye to the lateral corner over the brow then back to the inner corner.

2. Massage of the cheek area

- Middle and the ring fingers slid from the medial border of the brow of the affected side down along the nose then rotary movement across cheeks to temples was applied.

- The circular movement was applied by the middle and the ring fingers from the corner of the affected mouth up along the side of the nose then the fingers slide down to the corner of the affected mouth over the brow.

- The cheek of the affected side was lifted by the knuckles of one hand from the mouth to the ear, and then from the side of the nose to the top part of the ear.

\section{Massage of the lower facial area}

- $\quad$ Sliding movement by the middle and ring fingers of one hand was applied from the center of the upper lip of the affected side to the under lower lip and chin over the mouth then back to the center of the upper lip. The head was fixed by the other hand to avoid any movement during the massage.

- The lateral corner of the affected lip was pulled back into a smile position with rotary movement at the end of the pulling movement.

\section{Vibrator}

(Thrive; 50/60 Hz -AC 220 V- Japan) was applied over the affected side for 5 minutes with a rounded soft layer covering to avoid any pain or irritation of the skin during application.

\section{Statistical Analysis}

ANOVA-test was carried out for comparison of the 
subjects' characteristics between groups. Descriptive statistics of the number and frequencies of House Brackmann Scale grades were calculated. Kruskal-Wallis test was carried out for comparison of the median values of House Brackmann Scale grades between the four groups and was followed by the Mann-Whitney U test to identify the significant difference between every two groups. Friedman test was carried out for comparison between initial assessment, after 1 month and after 2 months measurements in each group and was followed by Wilcoxon Signed Ranks for pairwise comparison. The level of significance for all statistical tests was set at p < 0.05. All statistical measures were performed through the Statistical Package for Social Studies (SPSS), version 25 for windows.

\section{Results}

\section{- $\quad$ Subject characteristics}

Table (1) showed the subjects characteristics of groups A, B, C, and D. There was no significant difference between the four groups in the mean age, weight, and height ( $p>0.05)$.

\section{- $\quad$ Effect of Treatment on House Brackmann Scale Grades}

On the initial assessment higher percent of subjects were with grade $\mathrm{V}$ and IV. In group A 13 (26.5\%) subjects were with grade IV and 14 (28.6\%) subjects with grade V. In group B 14 (28.6\%) subjects were with grade IV and 15 (30.6\%) subjects with grade V. In group C 12 (24.5\%) subjects were with grade IV and 15 (30.6\%) subjects with grade V. In group D 11 (22.4\%) subjects were with grade IV and 15 (30.6\%) subjects with grade V.

After 1 month the percent of subjects with grades $\mathrm{V}$ and IV decreased markedly in groups B, C, and D while there was a small change in group $\mathrm{A}$ and the percent of grade I increased. The percent of grade I in group A was $18.4 \%$ while in groups B, C, and D were $30.6 \%, 32.7 \%$, and $34.7 \%$ respectively. The percent of grade IV in group A, $\mathrm{B}, \mathrm{C}$ and $\mathrm{D}$ were $24.5 \%, 2 \%, 18.4 \%$, and $14.3 \%$ respectively. Fig. (3).

After 2 months the percent of subjects with grade I increased markedly in group $\mathrm{B}$ with $0 \%$ of grades $\mathrm{V}$ and IV. The percent of grade I in group B was $71.4 \%$ while in groups A, C, and D were 28.6\%, 36.7\%, and $38.8 \%$ respectively. The percent of grade IV in groups $\mathrm{A}, \mathrm{B}, \mathrm{C}$, and $\mathrm{D}$ were $10.2 \%, 0 \%, 8.2 \%$, and $6.1 \%$ respectively. Table (3).

There was a significant difference in median values of House Brackmann Scale grades between the initial assessment, after 1 month and after 2 months in groups A, $B, C$, and D ( $<0.001)$. There was a significant decrease in the median values of the House Brackmann Scale grades after 2 months compared with that after 1 month and initial assessment in the four groups ( $p<0.001)$ and there was a significant improvement after 1 month compared with that at initial assessment $(\mathrm{p}<0.001)$. Table (4).

Table 1. Subject characteristics of groups A, B, C, and D

\begin{tabular}{|cccccc|}
\hline & \multicolumn{3}{c|}{$\overline{\mathrm{x}} \pm$ SD } \\
\cline { 2 - 7 } & Group A & Group B & Group C & Group D & p- value \\
\hline Age (years) & $39.81 \pm 10.61$ & $40.59 \pm 10.6$ & $40.06 \pm 12.88$ & $39.97 \pm 10.8$ & 0.98 \\
Weight (kg) & $82.12 \pm 2.07$ & $81.95 \pm 2.05$ & $81.73 \pm 1.76$ & $82.44 \pm 2.04$ & 0.34 \\
Height (cm) & $166.71 \pm 2.65$ & $167.14 \pm 4.46$ & $166.69 \pm 3.31$ & $166.87 \pm 3.07$ & 0.91 \\
\hline
\end{tabular}

$\overline{\mathrm{X}}$, Mean; SD, Standard deviation; p value, Probability value 
Table 2. Frequency distribution of House Brackmann Scale grades of groups A, B, C, and D at the initial assessment, after 1 month and after 2 months: Fig. (5)

\begin{tabular}{|c|c|c|c|c|}
\hline House Brackmann Scale & Group A & Group B & Group C & Group D \\
\hline Initial treatment & N (\%) & N (\%) & N (\%) & N (\%) \\
\hline Grade I & $0(0 \%)$ & $0(0 \%)$ & $0(0 \%)$ & $0(0 \%)$ \\
\hline Grade II & $9(18.4 \%)$ & $10(20.4 \%)$ & $11(22.4 \%)$ & $11(22.4 \%)$ \\
\hline Grade III & $7(14.3 \%)$ & $5(10.2 \%)$ & $6(12.2 \%)$ & $6(12.2 \%)$ \\
\hline Grade IV & $6(12.2 \%)$ & $5(10.2 \%)$ & $5(10.2 \%)$ & $6(12.2 \%)$ \\
\hline Grade V & $14(28.6 \%)$ & $15(30.6 \%)$ & $15(30.6 \%)$ & $15(30.6 \%)$ \\
\hline Grade IV & $13(26.5 \%)$ & $14(28.6 \%)$ & $12(24.5 \%)$ & $11(22.4 \%)$ \\
\hline \multicolumn{5}{|l|}{ After 1 month } \\
\hline Grade I & $9(18.4 \%)$ & $15(30.6 \%)$ & $16(32.7 \%)$ & $17(34.7 \%)$ \\
\hline Grade II & $2(4.1 \%)$ & $0(0 \%)$ & $1(2 \%)$ & $0(0 \%)$ \\
\hline Grade III & $5(10.2 \%)$ & $20(40.8 \%)$ & $0(0 \%)$ & $0(0 \%)$ \\
\hline Grade IV & $6(12.2 \%)$ & $0(0 \%)$ & $20(40.8 \%)$ & $21(42.9 \%)$ \\
\hline Grade V & $15(30.6 \%)$ & $13(26.5 \%)$ & $3(6.1 \%)$ & $4(8.2 \%$ \\
\hline Grade IV & $12(24.5 \%)$ & $1(2 \%)$ & $9(18.4 \%)$ & $7(14.3 \%)$ \\
\hline \multicolumn{5}{|l|}{ After 2 months } \\
\hline Grade I & $13(28.2 \%)$ & $35(71.4 \%)$ & $18(36.7 \%)$ & $19(38.8 \%)$ \\
\hline Grade II & $3(4.3 \%)$ & $0(0 \%)$ & $0(0 \%)$ & $15(30.6 \%)$ \\
\hline Grade III & $1(2 \%)$ & $13(26.5 \%)$ & 19 (38.8\%) & $6(12.2 \%)$ \\
\hline Grade IV & $20(40.8 \%)$ & $1(2 \%)$ & $3(6.1 \%)$ & $2(4.1 \%)$ \\
\hline Grade V & 7 (14.3\%) & $0(0 \%)$ & $5(10.2 \%)$ & $4(8.2 \%)$ \\
\hline Grade IV & 5 (10.2\%) & $0(0 \%)$ & $4(8.2 \%)$ & $3(6.1 \%)$ \\
\hline
\end{tabular}

Table 3. Comparison of median values of House Brackmann Scale grades between the initial assessment, after 1 month and after 2 months in group A, B, C and D

\begin{tabular}{|ccccccc|}
\hline \multirow{2}{*}{$\begin{array}{c}\text { House Brackmann } \\
\text { Scale }\end{array}$} & $\begin{array}{c}\text { Initial } \\
\text { treatment }\end{array}$ & $\begin{array}{c}\text { After 1 } \\
\text { month }\end{array}$ & $\begin{array}{c}\text { after 2 } \\
\text { months }\end{array}$ & \multicolumn{2}{c|}{ p-value } \\
\cline { 2 - 7 } & $\begin{array}{c}\text { Median } \\
\text { (IQR) }\end{array}$ & $\begin{array}{c}\text { Median } \\
\text { (IQR) }\end{array}$ & $\begin{array}{c}\text { Median } \\
\text { (IQR) }\end{array}$ & $\begin{array}{c}\text { Initial treatment } \\
\text { VS After 1 month }\end{array}$ & $\begin{array}{c}\text { Initial treatment } \\
\text { VS After 2 months }\end{array}$ & $\begin{array}{c}\text { After 1 month VS } \\
\text { After 2 month }\end{array}$ \\
\cline { 2 - 7 } Group A & $5(6,3)$ & $5(5,3)$ & $4(4,1)$ & 0.001 & 0.001 & 0.001 \\
Group B & $5(6,3)$ & $3(5,1)$ & $1(3,1)$ & 0.001 & 0.001 & 0.001 \\
Group C & $5(5,3)$ & $4(4,1)$ & $3(3,1)$ & 0.001 & 0.001 & 0.001 \\
Group D & $5(5,3)$ & $4(4,1)$ & $2(3,1)$ & 0.001 & 0.001 & 0.001 \\
\hline
\end{tabular}

p value, Probability value

Table 4. Comparison of median values of House Brackmann Scale grades between group A, B, C and D.

\begin{tabular}{|cccc|}
\hline & & p- value & after 2 months \\
\hline & Initial treatment & After 1 month & 0.001 \\
\cline { 2 - 4 } Group A Vs B & 0.81 & 0.001 & 0.03 \\
Group A Vs C & 0.79 & 0.05 & 0.005 \\
Group A Vs D & 0.66 & 0.02 & 0.001 \\
Group B Vs C & 0.62 & 0.15 & 0.007 \\
Group B Vs D & 0.5 & 0.22 & 0.12 \\
Group C Vs D & 0.86 & 0.8 & \\
\hline
\end{tabular}

p value, Probability value 
There was no significant difference in the House Brackmann Scale grades between groups at the initial assessment. After 1 month, there was a significant decrease in the median value of the House Brackmann Scale grade of group B compared with that of group A (p $<0.001$ ) and a significant decrease in the median value of House Brackmann Scale grade of group D compared with that of group $\mathrm{A}(\mathrm{p}=0.02)$ while there was no difference between group A and C, B and C, B and D and between C and D ( $\mathrm{p}>0.05$ ). After 2 months, there was a significant decrease in the median value of the House Brackmann Scale grade of group B compared with that of group A, C and $D(p<0.01)$ and a significant difference of the median value of the House Brackmann Scale grade of group $C$ and $D$ compared with that of group $A(p<0.05)$ while there was no difference between group $\mathrm{C}$ and $\mathrm{D}(\mathrm{p}>$ 0.05). Table (4) Fig. (4)

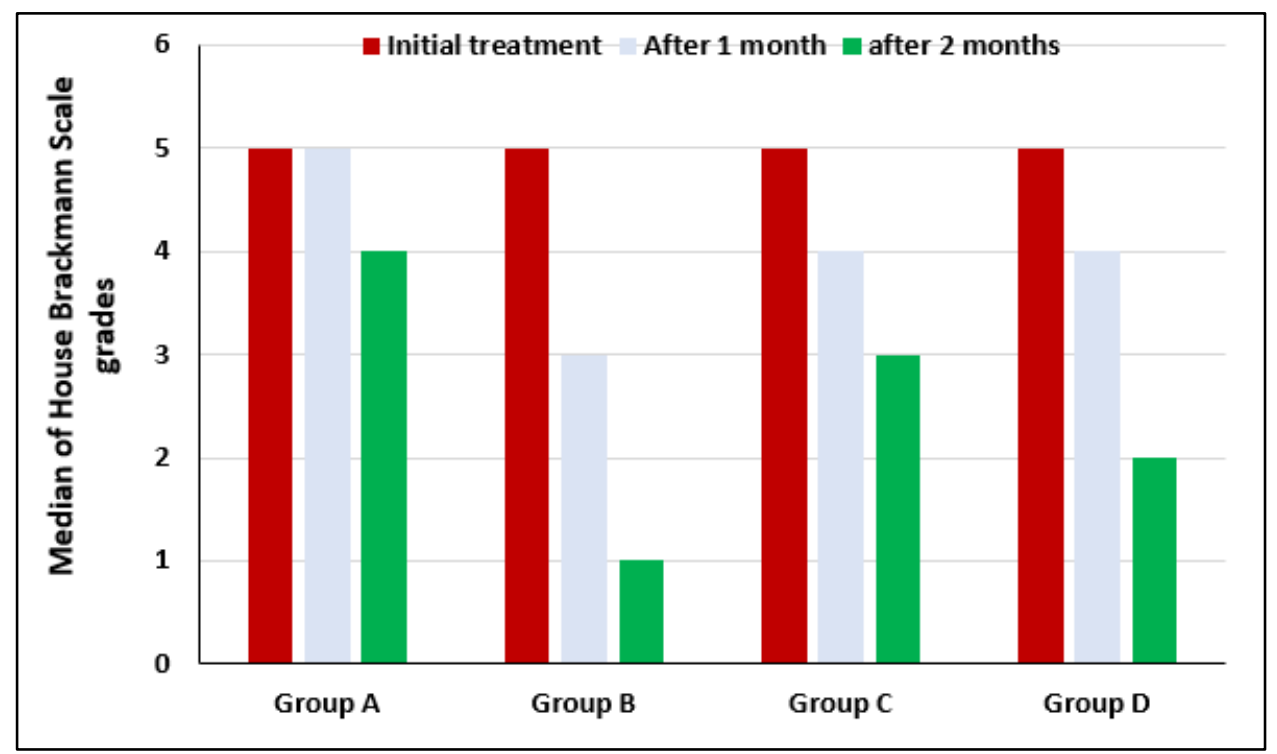

Figure 3. Median of House Brackmann Scale grades at initial, after 1 month and after 2 months in each group

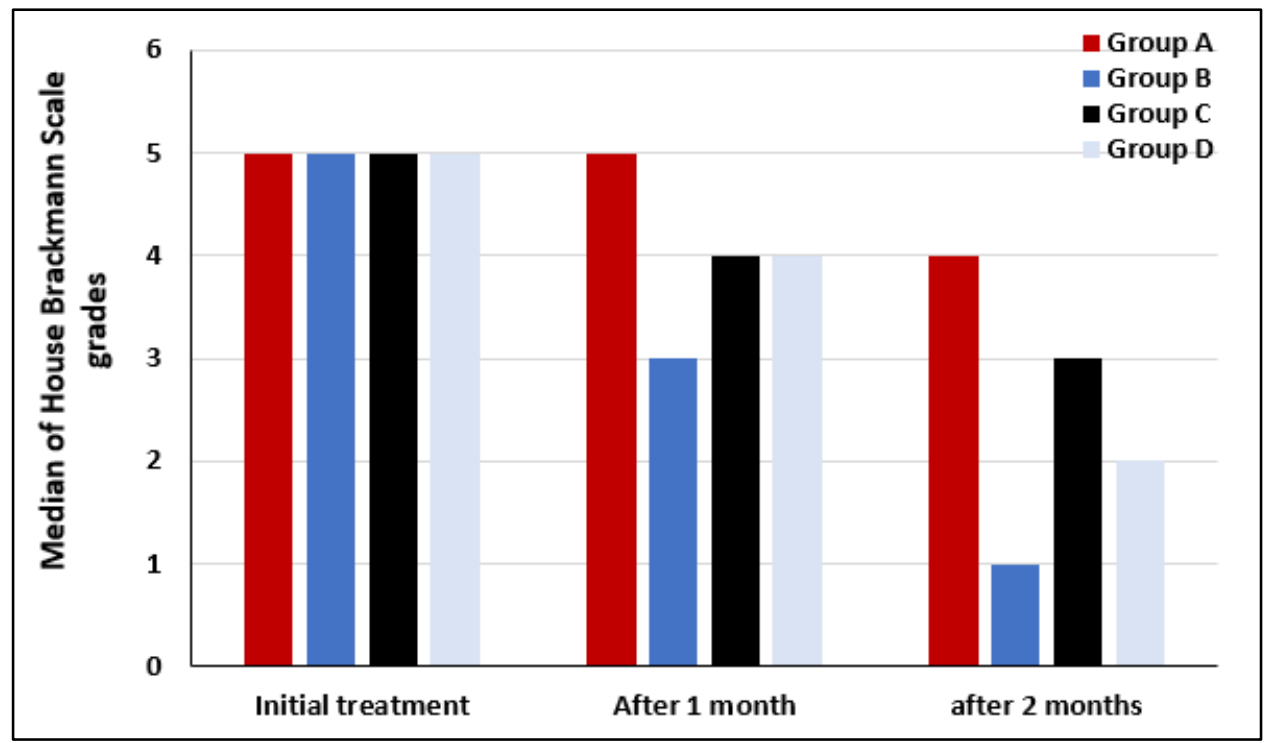

Figure 4. Median of House Brackmann Scale grades at initial, after 1 month and after 2 months between groups 


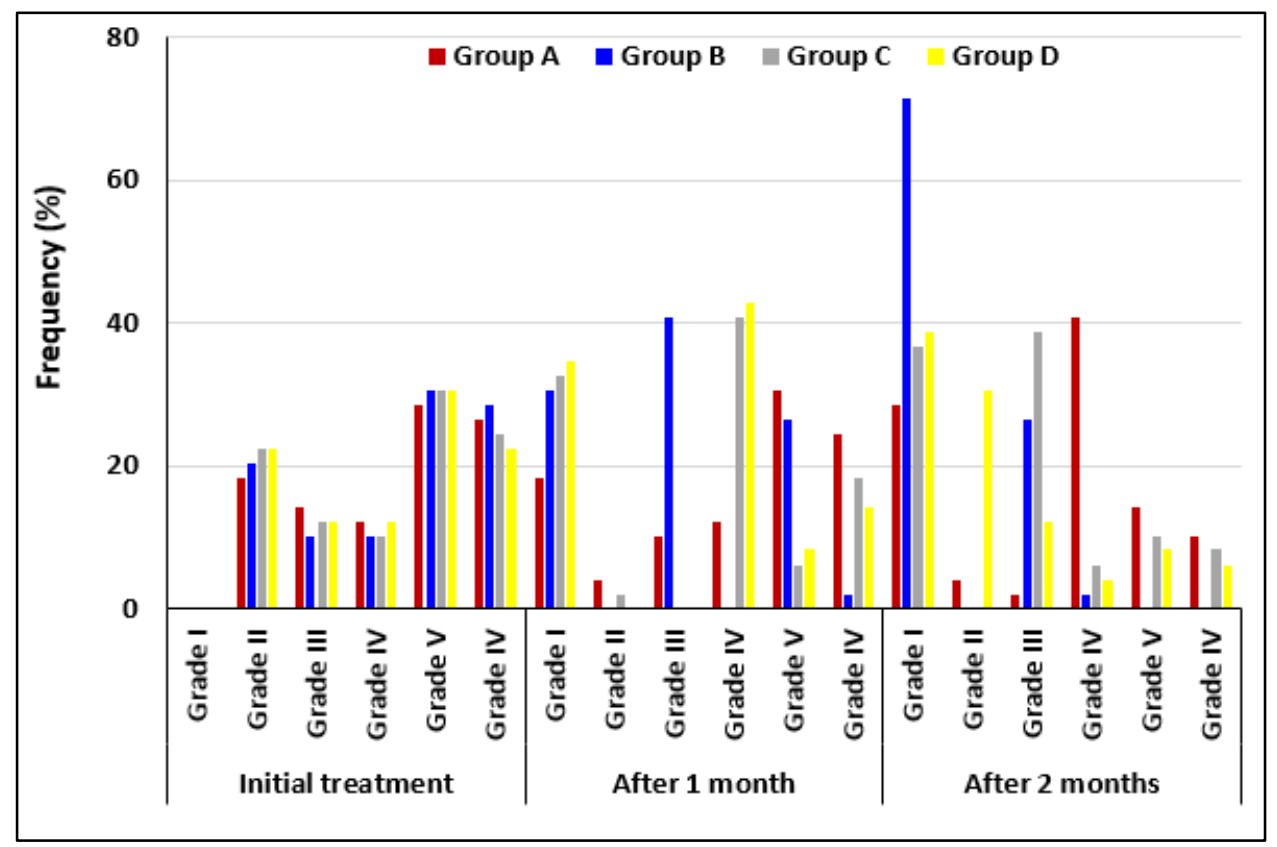

Figure 5. Frequency distribution of the House Brackmann Scale grades of the four groups

\section{Discussion}

Until now, the use of different physical methods in treating Bell's Palsy may be controversial because spontaneous healing of patients may occur without any treatment. Several studies have used treatment methods such as massage exercises, heat therapy and electrotherapy, but there have been some clinical trials that have supported the effectiveness of these methods and in particular, the use of electrotherapy that does not contain enough evidence to support its role in treating Bell's palsy. Therefore, the aim of this study was to investigate the effect of transcutaneous electrical nerve stimulation and faradic electrical stimulation on the recovery of Bell's palsy. This study was conducted on 196 patients with Bell's palsy. The program started after 2 weeks of the onset of Bell's palsy and all patients were assessed before and after one-month treatment protocol and at the end of the study by the House Brackmann scale, the most widely used scale for determining the severity degrees of Bell's palsy.

The results of this study revealed that there was a statistically significant improvement in the House Brackmann score after one month and at the end of the treatment in the four groups as following:

\section{Conventional Therapy Group}

After one-month treatment

All patients ( $\mathrm{n}=9$ ) with grade II (7/8 score) have improved to grade I ( $8 / 8$ score and their ages ranged from 22-50 y), 2 patients with grade III (6/8) have improved to grade II (7/8 score with the age of 26y), while 5 patients with grade III (6/8 score with age ranged from 30 to $55 y)$ have no improvement. There was no improvement in all patients $(n=6)$ with grade IV (3/8 score with age ranged from 22 to $60 \mathrm{y})$, no improvement in all patients $(\mathrm{n}=14)$ with grade V (2/8 with age ranged from 34 to $60 \mathrm{y}$ ), and no improvement in patients $(\mathrm{n}=12)$ with grade VI $(0 / 8$ score with age ranged from 31 to $59 \mathrm{y}$ ) only one patient has improved to grade V (16 y).

\section{After two-months treatment}

4 patients, two 26 years old patients with grade II, and two patients, between 40 and 55 years old, with grade III, have improved to grade I ( $8 / 8$ score) while 3 patients, between 30 and 41years old, have improved from grade III (6/8 score) to grade II (7/8 score), 5 patients, between 31 and 60 years old, with grade IV(3/8 score) showed no improvement, while one patient,22 years old, has improved from grade IV (3/8 score) to grade III. All patients, between 34 and 60 years old, $(\mathrm{n}=14)$ with grade $\mathrm{V}$ ( $2 / 8$ score) have improved to grade IV (4/8 score). 7 patients, between 31 and 46 years old, with grade VI (0/8 score) have improved to grade $\mathrm{V}$ (2/8 score) while one patient, 16 years old, has improved from grade V (2/8 score) to grade IV (4/8 score). Finally, five patients, between 46 and 59 years old, with grade VI (0/8 score) showed no improvement.

\section{Transcutaneous Electrical Nerve Stimulation Group}

After one-month treatment

All patients $(\mathrm{n}=10)$ with grade II (7/8 score) have improved to grade I ( $8 / 8$ score with ages ranged from 20 to $50 \mathrm{y})$; there was an improvement in all patients $(\mathrm{n}=5)$ 
with grade III (6/8 score) to grade I (8/8 score with ages ranged from 24-54 y); also, there was an improvement in all patients $(n=5)$ with grade IV ( $3 / 8$ score) to grade III (6/8 score with ages ranged from 22 to $58 \mathrm{y}$ ), an improvement in all patients $(\mathrm{n}=15)$ with grade $\mathrm{V}(2 / 8$ score) to grade III (6/8 score with ages ranged from 24 to $50 \mathrm{y})$, and an improvement in patients $(\mathrm{n}=13)$ with grade VI ( $0 / 8$ score) to grade V (2/8 score with ages ranged from 25 to $58 \mathrm{y}$ ), while one patient, 60 years old, with grade VI (0/8 score) showed no improvement.

\section{After two-months treatment}

All patients $(n=20)$ with grade III (6/8 score) have improved to grade I ( $8 / 8$ score with ages ranged from 22 to $58 \mathrm{y})$; there was an improvement in all patients $(n=13)$ with grade V (2/8) to grade III (6/8 score with ages ranged from 22 to $58 \mathrm{y}$ ); while one patient, 60 years old, with grade VI (0/8 score) has improved to grade IV (4/8 score).

\section{Faradic Current Stimulation Group}

After one-month treatment

All patients ( $\mathrm{n}=11)$ with grade II (7/8 score) have improved to grade I (8/8 score with ages ranged from 15 to $56 \mathrm{y})$; there was an improvement in patients $(\mathrm{n}=5)$ with grade III (6/8) to grade I (8/8 score with ages ranged from 22 to $50 \mathrm{y}$ ), while one patient, 60 years old, with grade III has improved to grade II (7/8 score). There was no improvement in all patients $(\mathrm{n}=5)$ with grade IV ( $3 / 8$ score with ages ranged from 25 to 56 y), just very little improvement in the forehead movement and eye closure, while there was an improvement in all patients $(n=15)$ with grade V (2/8 score) to grade IV (4/8 with ages ranged from 26-58 y), 3 patients with grade VI ( 0/8 score) improved to grade $\mathrm{V}$ (2/8 score with ages ranged from 22 to $26 \mathrm{y}$ ), while 9 patients with grade VI have no improvement (0/8 score with ages ranged from 32 to $60 \mathrm{y})$.

\section{After two-months treatment}

All patients ( $\mathrm{n}=19)$ with grade IV (4/8 score) have improved to grade III (6/8 score with ages ranged from 29 to $58 \mathrm{y}$ ), while one patient, 26 years old, has improved from grade IV (4/8 score) to grade I (8/8 score). 4 patients with grade VI have no improvement ( $0 / 8$ score with ages ranged from 56 to $60 \mathrm{y})$, while 5 patients have improved from grade VI ( $0 / 8$ score) to grade V(2/8 score with ages ranged from 32 to 53y), and 3 patients with grade VI (0/8 score) have improved to grade IV (4/8 score with ages ranged from 22 to $26 \mathrm{y}$ ).

\section{Transcutaneous Electrical Nerve Stimulation Group plus Faradic Current Stimulation}

\section{After one-month treatment}

All patients $(\mathrm{n}=11)$ with grade II (7/8 score) have improved to grade I (8/8 score with ages ranged from 24 to $60 \mathrm{y})$, there was an improvement in all patients $(\mathrm{n}=6)$ with grade III (6/8) to grade I (8/8 score with ages ranged from 22 to $51 \mathrm{y}$ ), while there was no improvement in all patients $(n=6)$ with grade IV (3/8 score with ages ranged from 28 to $57 \mathrm{y}$ ) just very little improvement in forehead movement and eye closure. There was an improvement in all patients ( $\mathrm{n}=15)$ with grade $\mathrm{V}$ (2/8 score) to grade IV (4/8 with ages ranged from 18 to $50 \mathrm{y}$ ), 4 patients with grade VI ( $0 / 8$ score) have improved to grade V (2/8 score with ages ranged from 15 to 28 y), while 7 patients with grade VI have no improvement (0/8 score with ages 43 to $60 \mathrm{y})$.

\section{After two-months treatment}

6 patients with grade IV (4/8 score) have improved to grade III (6/8 score with ages ranged from 28 to $57 \mathrm{y})$, while 15 patients have improved from grade IV (4/8 score) to grade II (7/8 score with ages ranged from of 18 to $50 \mathrm{y}$ ). 2 patients with grade VI have improved to grade IV (4/8 score with ages ranged from of 20 to 28y). 2 patients, 15 years old have improved from grade $\mathrm{V}$ ( $2 / 8$ score) to grade I ( $8 / 8$ score). 4 patients with grade VI ( $0 / 8$ score) have improved to grade $\mathrm{V}$ (2/8 score with ages ranged from of 43 to $51 \mathrm{y}$ ) while 2 patients have improved from grade $\mathrm{V}(2 / 8$ score with ages ranged from 20 to $28 \mathrm{y})$ and 3 patients with grade VI (0/8 score with ages ranged from 57 to $60 y$ ) showed no improvement.

Regarding the duration of electrical stimulation either TENS or faradic current, 20 minutes was selected for stimulation in the three groups by 20 minutes for the TENS group, 20 minutes for the faradic stimulation group, and 10 minutes faradic stimulation +10 minutes TENS in the third group. The explanation for these selections was that the previous studies investigated the effect of TENS for 30 minutes with 10 us (microsecond) pulse duration on Bell's palsy and some other studies recommended the use of faradic current for 10 to 20 minutes with a pulse duration of $1 \mathrm{~ms}$ (millisecond) at the early stage to avoid muscle fatigue as the nerve is still in the acute phase [22].

The treatment in this study started after 2 weeks of onset and it is in contrast to Diels [23] who recommended rest and avoid the use of facial exercises with or without electrical stimulation during the first 2 weeks after the onset. The justification for this was that the nerve is in the inflammatory phase where the application of exercises and ES leads to more inflammation that reduces the healing period, as well as complications that may occur. On the contrary, other studies have recommended the use of physical therapy after 2 weeks to promote recovery and increase nerve regeneration $[13,17]$.

Manikandan [24] demonstrated the role of physiotherapy in treating Bell's palsy and stated that physiotherapy has been used widely as a treatment approach for Bell's palsy since 1927 because of its effect on enhancing the recovery of these cases. Finsterer [25] summarized the benefits of physiotherapy in that it helps reduce pain and fibrosis, promote nerve regeneration, 
develop facial muscle tone, and Finsterer suggested that the time of the sessions should be related to the severity of the symptoms. In the same context, Nicastri et al. [26] stated that the use of physiotherapy has a very important effect on the severity of the symptoms in Bell's palsy, especially when applied immediately after the onset of the paralysis. Also, Quinn and [27] concluded that the use of electrical stimulation or high voltage galvanic currents can help in nerve regeneration by reducing edema and their use is not recommended in the early stages.

Pereira et al. [28] stated that introducing exercise therapy in the treatment of Bell's palsy is an effective method which it distributes oxygen to facial muscles of the affected side to maintain muscle function and enhancing recovery.

Banu et al. [29] reported that Infrared Radiation with proprioceptive neuromuscular facilitation (PNF) exercises plus drugs showed an early recovery of $43.33 \%$ over PNF exercise plus drugs in which there was an improvement of $20 \%$. This is due to the possibility of the infrared radiation (wavelength from $770 \mathrm{~nm}$ to $1200 \mathrm{~nm}$ ) to increase blood circulation, subsequently affecting the reduction of edema by stimulating the absorption of the inflammatory fluid exudate [30].

Alakram and Puckree [17] stated that although the use of TENS in early stages of Bell's palsy (after 2 weeks of onset) is safe, it is indistinguishable from spontaneous Bell's palsy recovery. Firas et al. [31] reported that ES can be used in chronic Bell's palsy as it can protect facial muscles from atrophy or fibrosis and improve functional outcomes, especially in cases of total paralysis. Also, Gittens et al. [32] found that the use of TENS in chronic cases for 3 months could improve the voluntary movements of the eyelid which may be attributed to a reduction in eyelid stiffness. Additionally, Shafshak [13] concluded that ES could support and improve axonal restoration and suggested that TENS could be used in treating Bell's palsy with a pulse duration of no more than $1 \mathrm{~ms}$.

Narin and Barutçua [33] found that there was a significant improvement in facial muscle function as well as facial symmetry in the experimental group that received faradic current at $100 \mathrm{~Hz}$ for 20 minutes after reconstructive surgery of temporal muscle. In addition, Manikandan [24] reported that patients treated with feedback exercises have improved facial muscle symmetry compared to patients that have been treated with conventional therapy in addition to ES. Also, Dalla et al. [34] showed that the combination of ES and feedback exercises was more effective than a massage in treating Bell's palsy.

In contrast, Dalla et al [35] conducted a study on 102 patients with Bell's palsy and reported that after 12 months of rehabilitation there was no statistical difference between the two experimental groups (axonotmesis lesion) that received ES only and ES with feedback exercises while the patients in the control group (neuropraxia lesion) were completely recovered within 20 days after the onset of bell's palsy without any treatment methods. Moreover, Alakram and Puckree reported that there was no difference between the first group that received conventional therapy consisting of facial exercises, heating therapy, and massage for a specific time, and the second group who received the same conventional therapy in addition to a 30 minutes TENS. This may be related to the small sample selected for their study (8 patients in each group) as well as applying electrotherapy sessions once a week for 3 months.

\section{Conclusions}

Although there was no difference between all groups on grades II, and III, TENS has a noticeable effect on grade IV, V, VI of HB scale from at least a month after the application, while other groups have an uneven effect on these grades. Therefore, it concluded that the application of TENS and faradic current appear to be safe methods in treating Bell's palsy as they reduce the severity of its symptoms, especially in the early stages, with a preference for applying TENS over faradic current alone or with TENS.

\section{Acknowledgements}

We express our sincere gratitude to all the patients, neurologists, and physiotherapists at Toukh General Hospital for their kind cooperation during this study.

\section{Conflict of Interest}

The author declares that there is no conflict of interest.

\section{REFERENCES}

[1] Fuller G, Morgan C. Bell's palsy syndrome: mimics and chameleons. Pract Neurol. 2016; 16(6): 439-444. doi:10.1136/practneurol-2016-001383.

[2] Madhok VB, Gagyor I, Daly F, et al. Corticosteroids for Bell's palsy (idiopathic facial paralysis). Cochrane Database Syst Rev. 2016;7(7):CD001942. Published 2016 Jul 18. doi:10.1002/14651858.CD001942.pub5.

[3] Hussain A, Nduka C, Moth P, Malhotra R. "Bell's facial nerve palsy in pregnancy: a clinical review". Journal of Obstetrics and Gynaecology: The Journal of the Institute of Obstetrics and Gynaecology. 2017; 37 (4): 409-15. doi:10.1080/01443615.2016.1256973.

[4] Jain V, Deshmukh A, Gollomp S. Bilateral facial paralysis: case presentation and discussion of differential diagnosis. $\mathrm{J}$ Gen Intern Med. 2006;21(7):C7-C10. doi:10.1111/j.1525-1 497.2006.00466. 
[5] Gagyor I, Madhok VB, Daly F, et al. Antiviral treatment for Bell's palsy (idiopathic facial paralysis). Cochrane Database Syst Rev. 2015;(11):CD001869. Published 2015 Nov 9. doi:10.1002/14651858.CD001869.pub8.

[6] Kasse CA, Ferri RG, Vietler EYC, Leonhardt FD, Testa JRG, Cruz OLM. "Clinical data and prognosis in 1521 cases of Bell's palsy". International Congress Series. 2003; 1240: 641-47. doi:10.1016/S0531-5131(03)00757-X.

[7] Hato N, Yamada H, Kohno $\mathrm{H}$, et al. Valacyclovir and prednisolone treatment for Bell's palsy: a multicenter, randomized, placebo-controlled study. Otol Neurotol. 2007; 28(3):408-413. doi:10.1097/01.mao.0000265190.29969.12.

[8] Zandian A, Osiro S, Hudson R, et al. The neurologist's dilemma: a comprehensive clinical review of Bell's palsy, with emphasis on current management trends. Med Sci Monit. 2014; 20: 83-90. Published 2014 Jan 20. doi:10.12659/MSM.889876.

[9] Peitersen E. Bell's palsy: the spontaneous course of 2,500 peripheral facial nerve palsies of different etiologies. Acta Otolaryngol Suppl. 2002;(549):4-30. https://pubmed.ncbi.nl m.nih.gov/12482166.

[10] Baugh RF, Basura GJ, Ishii LE, et al. Clinical practice guideline: Bell's palsy. Otolaryngol Head Neck Surg. 2013;149(3 Suppl): S1-S27. doi:10.1177/019459981350596 7.

[11] Garro A, Nigrovic LE. Managing Peripheral Facial Palsy. Annals of Emergency Medicine.2018; 71 (5): 618-23. doi:10.1016/j.annemergmed.2017.08.039.

[12] Elliott JM (2006). Physiotherapy treatment of Bell's palsy: a case report. New Zealand Journal of Physiotherapy. 2006; 34: 167-172. https://www.thefreelibrary.Com/Physiotherap $\mathrm{y}+$ treatment + of + Bell\%27s+palsy\%3a+a +case+report.-a0160592687.

[13] Shafshak TS. The treatment of facial palsy from the point of view of physical and rehabilitation medicine. Eura Medicophys. 2006; 42(1): 41-47. https://pubmed.ncbi.nlm.n ih.gov/ 16565685.

[14] Teixeira LJ, Valbuza JS, Prado GF. Physical therapy for Bell's palsy (idiopathic facial paralysis). Cochrane Database Syst Rev. 2011;(12):CD006283. Published 2011 Dec 7. doi:10.1002/14651858.CD006283.pub3.

[15] House JW, Brackmann DE. Facial nerve grading system. Otolaryngol Head Neck Surg. 1985; 93(2): 146-147. doi:10.1177/019459988509300202.

[16] Sajadi MM, Sajadi MR, Tabatabaie SM. The history of facial palsy and spasm: Hippocrates to Razi. Neurology. 2011; 77(2): 174-178. doi: 10.1212/WNL.0b013e3182242d 23.

[17] Alakram P, Puckree T. Effects of electrical stimulation on House-Brackmann scores in early Bell's palsy. Physiother Theory Pract. 2010;26(3):160-166. doi:10.3109/095939809 02886339 .

[18] Random Assignment | Best Random Tools. https://www.bestrandoms.com/random-assignment..

[19] Coulson SE, Croxson GR, Adams RD, O'Dwyer NJ. Reliability of the "Sydney," "Sunnybrook," and "House Brackmann" facial grading systems to assess voluntary movement and synkinesis after facial nerve paralysis. Otolaryngology--head and Neck Surgery: Official Journal of American Academy of Otolaryngology-head and Neck Surgery. 2005 Apr; 132(4): 543-549. DOI:10.1016/j.otohns 2005.01.027.

[20] Chung How Kau, Stephen Richmond. Three-Dimensional Imaging for Orthodontics and Maxillofacial Surgery. Wiley-Blackwell: United Kingdom. 2011.https://www.wile y.com/enus/Three+Dimensional+Imaging+for+Orthodontic s+and+Maxillofacial+Surgery-p-9781405162401.

[21] Kang TS, Vrabec JT, Giddings N, Terris DJ. Facial nerve grading systems (1985-2002): beyond the House-Brackmann scale. Otol Neurotol. 2002; 23(5): 767-771. doi: 10.1097/00129492-200209000-00026.

[22] Morral-Fernandez A. Electro diagnostico y electro estimulation de masculos denervados. Fisioterpia. 2001; 23: 23-35. https://doi.org/10.1016/S0211-5638(01)72970-7.

[23] Diels JH 2000 New concepts in Nonsurgical Facial nerve Rehabilitation. Advances in - Otolaryngology Head and Neck Surgery 9: 289-311.http://bellspalsy.ws/facial-retraini ng.

[24] Manikandan N. Effect of facial neuromuscular re-education on facial symmetry in patients with Bell's palsy: a randomized controlled trial. Clin Rehabil.2007;21(4):338-3 43. doi:10.1177/0269215507070790.

[25] Finsterer J. Management of peripheral facial nerve palsy. Eur Arch Otorhinolaryngol. 2008; 265(7): 743-752. doi:10.1007/s00405-008-0646-4.

[26] Nicastri M, Mancini P, De Seta D, et al. Efficacy of early physical therapy in severe Bell's palsy: a randomized controlled trial. Neurorehabil Neural Repair. 2013; 27(6): 542-551. doi:10.1177/1545968313481280.

[27] Quinn R, Cramp F. The efficacy of electrotherapy for Bell's palsy: a systematic review. Physical Therapy Reviews,2003; 8(3): 151-164 DOI: 10.1179/108331903225002470.

[28] Pereira LM, Obara K, Dias JM, Menacho MO, Lavado EL, Cardoso JR. Facial exercise therapy for facial palsy: systematic review and meta-analysis. Clin Rehabil. 2011; 25(7): 649-658. doi:10.1177/0269215510395634.

[29] Banu, Hashina, Sohely Rahman, Shahadat Hossain, Jebunnesa, Ehsanul Khan, Khurshid Mahmood, DM Rahman, and Monjur Ahmed. 2017. "Effect of Infrared Radiation (IRR) on Patients with Bell's Palsy”. Bangladesh Medical Journal. 2017;46(1),1-6. https://doi.org/10.3329/b mj.v46i1.34630.

[30] Randall L. Braddom. Physical Medicine and Rehabilitation. Saunders Elsvier.2007; 3(21): 463. https://www.elsevier.co $\mathrm{m} /$ books/physical-medicine-and-rehabilitation/braddom/97 8-1-4377-0884-4.

[31] Firas Sarhan, Ahmad Saif, Danah Saif. Bell's palsy: an overview. British Journal of Neuroscience Nursing, 2012; 8(4): 163-168 DOI: 10.12968/bjnn.2012.8.4.163. https://doi. org/10.12968/bjnn.2012.8.4.163.

[32] Gittins J, Martin K, Sheldrick J, Reddy A, Thean L. Electrical stimulation as a therapeutic option to improve eyelid function in chronic facial nerve disorders. Invest Ophthalmol Vis Sci. 1999;40(3):547-554. https://pubmed.n cbi.nlm.nih.gov/10067956. 
[33] Narin S, Barutu A. Treatment of prolonged facial paralysis with temporalis myoplasty and electrical stimulation. J Neurol Sci (Turkish). 2012; 28: 513-519. https://www.sema nticscholar.org/paper/Treatment-of-Prolonged-Facial-Paral ysis-With-and-NARBarutçu/64100c954fcf34e9c7820d7c54 faea d7e62ac523.

[34] Dalla Toffola E, Bossi D, Buonocore M, Montomoli C,
Petrucci L, Alfonsi E. Usefulness of BFB/EMG in facial palsy rehabilitation. Disabil Rehabil. 2005; 27(14):809-815. doi:10.1080/09638280400018650.

[35] Dalla Toffola E, Tinelli C, Lozza A, et al. Choosing the best rehabilitation treatment for Bell's palsy. Eur J Phys Rehabil Med. 2012; 48(4): 635-642. https://pubmed.ncbi.nl m.nih.gov/22522431. 